\title{
Technical note: Validation of a behavior-monitoring collar's precision and accuracy to measure rumination, feeding, and resting time of lactating dairy cows
}

\author{
L. N. Grinter, M. R. Campler, and J. H. C. Costa* \\ Department of Animal and Food Sciences, University of Kentucky, Lexington 40546
}

\begin{abstract}
Precision dairy technology is important because of the possibility to continuously and accurately measure behavior, biometrics, and productivity on commercial and research dairy farms by an automated method with minimal human intervention. The behavior-monitoring collar (BMC) used in this study is a commercially available precision dairy technology (MooMonitor+, Dairymaster, Co. Kerry, Ireland), designed to measure rumination, heat detection, feeding, and resting behavior of dairy cows. The study objective was to compare cow behavior measured by the BMC with visual observations. Twenty-four lactating, group-housed, Holstein dairy cows (mean \pm standard deviation; days in milk: $196 \pm 101$; parity: $2.0 \pm 1.1$; milk yield: $40.0 \pm 9.8$ $\mathrm{kg} / \mathrm{d}$ ) were randomly selected for observation at the University of Kentucky's research dairy farm, Lexington). Behavior-monitoring collars were assigned to cows as per farm protocol. Each cow was observed for 240 min within $1 \mathrm{~d}$ (0700 to $0900 \mathrm{~h}$, and 1900 to $2100 \mathrm{~h}$ ). Recordings of rumination, feeding, and resting time (min) by the BMC were compared with visual observation using Pearson correlation, concordance correlation coefficient (CCC), linear regression, and Bland-Altman plots for validation of precision and accuracy. Data from the BMC were considered precise if the correlation coefficient and coefficient of determination were high $(>0.70)$, and mean bias from the Bland-Altman plots included zero with the $95 \%$ interval of agreement. The BMC was considered accurate if the slope from the linear regressions did not differ significantly from 1 , and the CCC $\left(\rho_{c}\right)$ were at least moderate $(>0.90)$. We found very high Pearson correlation coefficients $(0.99$, 0.93 , and 0.94$)$ and coefficients of determination (0.97, 0.85, and 0.88) for rumination, feeding, and resting, respectively. Bland-Altman plots were acceptable; the
\end{abstract}

Received August 16, 2018.

Accepted December 17, 2018.

*Corresponding author: costa@uky.edu plots did not show any bias. The Bland-Altman mean differences \pm standard deviation (BMC - observation) were $-7.57 \pm 6.31,15.81 \pm 11.84$, and $-13.03 \pm 9.37$ min, respectively. The Bland-Altman plot's $95 \%$ interval of agreement encompassed $100 \%$ of the observations of resting time, and all but one cow's observations for both rumination and feeding time. The slope of the linear regression, however, was different than 1 for all behaviors, and rumination was the only behavior with moderate CCC. In summary, this study validates the high precision of rumination, resting, and feeding behaviors measured by a BMC in lactating dairy cows. Key words: precision dairy farming, MooMonitor+, accelerometer

\section{Technical Note}

Wearable, behavior-monitoring, precision dairy technologies (PDT) autonomously monitor cow behavior, while minimizing human interference or human error. Common commercially available wearable PDT for behavior monitoring include collars, ear tags, and leg bands; however, others are also available (Borchers et al., 2016; Caja et al., 2016). Behaviors such as rumination, feeding, and resting time are among the variables that PDT can record in cows. Monitoring dairy cattle behavior using PDT gives producers or researchers an early alert to provide attention to an animal that has deviated from normal patterns of behavior (Norton and Berckmans, 2017). Predominant causes for deviations in behavior are estrus (Dolecheck et al., 2015; Shahriar et al., 2016) or illness (Schirmann et al., 2016; Stangaferro et al., 2016a).

It is important to validate all PDT to understand their precision and accuracy before taking measurements or applying them to cattle management or research. Validation compares the PDT with a known (or gold standard) measurement of behavior (such as visual observation) to understand its precision and accuracy (Norton and Berckmans, 2017). To validate precision of PDT against visual observation, previous studies have 
successfully used Bland-Altman plots (Schirmann et al., 2009; Elischer et al., 2013; Zehner et al., 2017), correlation coefficients, or regressions (Bikker et al., 2014; Wolfger et al., 2015; Borchers et al., 2016). Accuracy has been assessed in previous validation studies of PDT by analyzing the slope of the regression line (AmbrizVilchis et al., 2015; Chizzotti et al., 2015). However, accuracy is often not reported or tested in studies validating PDT. Therefore, the purpose of this study was to validate the precision and accuracy of a behaviormonitoring collar (BMC; MooMonitor+, Dairymaster, Co. Kerry, Ireland) measuring ruminating, resting, and feeding time in lactating dairy cows.

The study was conducted at the University of Kentucky Coldstream Research Dairy Farm (Lexington), and approved by the Institutional Animal Care and Use Committee (protocol number 2017-2724). Cows were housed in a compost bedded-pack barn that was tilled twice per day. The herd was milked twice/d (0430 and $1530 \mathrm{~h}$ ). Cows were fed a TMR, formulated to follow the NRC guidelines (NRC, 2001) to meet or exceed the requirements of lactating dairy cows producing at least $39 \mathrm{~kg}$ of milk/d. All cows were fed the same TMR twice per day (approximately at 0730 and $1430 \mathrm{~h}$ ) for the duration of the study, via a feed alley with headlocks, and had ad libitum access to fresh water from water troughs.

The number of cows on the study was determined following methods of Friedman (1982) and adapted by Borchers et al. (2016). Twenty-four cows were determined necessary to enroll to the study from a power test, calculated to attain power $(1-\beta)$ of 0.90 , and a type I error probability $(\alpha)$ of 0.05 (2-sided) utilizing variances of data reported in Borchers et al. (2016).

The 24 Holstein cows were selected by using a criteria requiring cows from the first home pen (first milking group at 0530 and $1630 \mathrm{~h}$ ) to be over 30 DIM and have a locomotion score of 1 or 2 . Cow locomotion score was obtained weekly using a 5 -point scoring method $(1=$ normal, $2=$ mildly lame, $3=$ moderately lame, $4=$ lame, and $5=$ severely lame, developed by Sprecher et al. (1997). Cows were randomly selected weekly using the set criteria for observation times occurring in the next $7 \mathrm{~d}$ to ensure cows remained eligible for the study. The 24 cows (mean \pm SD; DIM: $196 \pm$ 101; parity: $2.0 \pm 1.1$; and milk yield: $40.0 \pm 9.8 \mathrm{~kg} / \mathrm{d}$ ) were fitted with BMC $196.2 \pm 101.2$ d before observation. One cow chosen changed eligibility (developed a locomotion score of $\geq 3$ ) and therefore was replaced to retain the required sample size of 24 cows.

The mechanical measurements made by the BMC used in this study were recorded by the working part of the device $(121 \mathrm{~g} ; 7.25 \times 8 \times 3.25 \mathrm{~cm})$, positioned lon- gitudinally in the middle of the left side of the collar. A micro electro-mechanical system accelerometer is built into the device; the accelerometer continuously records the animal's movements, which are translated by an algorithm into a nonstop record of behavior. Data were wirelessly transmitted to a base station (located in the barn) every 15 min (as opposed to being stored on the device). The base station in turn transmits data to an Internet-based cloud service (online storage service). In the event of short-term (depending on herd size) connection failure to the Internet-based cloud service, the barn base station can store data and upload when the connection is restored. Life expectancy of batteries in these BMC is up to $10 \mathrm{yr}$. Behavior-monitoring collars were synchronized (for time and communication to the base station) up to $7 \mathrm{~d}$ before being observed. Any BMC failing to synchronize was replaced, and the corresponding cow was not reconsidered for observation until $21 \mathrm{~d}$ post-BMC replacement to allow the device to calculate baseline values.

Every cow was observed for two 2-h periods (0700 to $0900 \mathrm{~h}$, and 1900 to $2100 \mathrm{~h}$ ) within a 24-h timeframe to attempt to record a range of behaviors and account for diurnal variation (DeVries et al., 2003). Observations occurred between September 2017 and April 2018. One cow was observed at a time. All observations were completed in the cow's home pen (approximately 621$\mathrm{m}^{2}$ pen with a $202-\mathrm{m}^{2}$ feed alley, stocked with approximately $58 \pm 4$ cows). A single observer completed all observations for the study to avoid any inter-observer variance. The observer was positioned within a clear field of view of the focal cow to ensure constant view of the cow's head and muzzle, and without interfering with the cow's natural behavior. A multifunction, radio frequency synchronized atomic watch (Casio, Casio America Inc., Dover, NJ) was used to manually record durations of behavior (hh:mm:ss). The rumination, resting, and feeding behaviors were observed following a previously constructed ethogram, which is provided in Table 1.

Each cow's 240-min observation was summed by behavior (rumination, feeding, and resting) to assess agreement of visually recorded behavior to BMC data. All analyses were performed with SAS (version 9.4, SAS Institute Inc., Cary, NC), using the cow as the experimental unit.

Recorded data from the BMC were supplied from the company in 15-min blocks (summed by behavior). No data were missing from the BMC for any period.

Descriptive analyses were performed, and data were verified for normality using the PROC UNIVARIATE procedure and probability distribution plots. No outliers were detected (data points beyond 3 SD from the 
Table 1. Ethogram of behavior classification for visual observations

\begin{tabular}{ll}
\hline Behavior & Classification \\
\hline Ruminating & $\begin{array}{l}\text { Regurgitation and remastication of a bolus with a rhythmic jaw movement. A break between bolus exchanges of } \geq 5 \mathrm{~s} \text { was } \\
\text { recorded as a different activity. }\end{array}$ \\
Resting & $\begin{array}{l}\text { Includes lying and standing behavior. A lying event was defined as any time the cow was lying with all } 4 \text { limbs on the } \\
\text { ground. Lying events began when the posterior end contacted the ground, and finished when the posterior end was off the } \\
\text { ground. A standing activity was categorized by the cow standing static for } \geq 5 \mathrm{~s}, \text { with all } 4 \text { hooves on the ground. }\end{array}$ \\
$\begin{array}{l}\text { Feeding } \\
\text { Other }\end{array}$ & Any other activity such as drinking, walking, grooming, licking, rubbing, and interacting with other cows.
\end{tabular}

mean) and all met normality assumptions; therefore, no transformations were deemed necessary.

Precision was analyzed by a Pearson correlation coefficient (r) and linear regression coefficient of determination $\left(\mathbf{R}^{2}\right)$. Results of the Pearson correlation coefficient and coefficient of determination were categorized by Hinkle $(1988 ; 0.00$ to $0.30=$ namely negligible; 0.30 to $0.50=$ low; 0.50 to $0.70=$ moderate; 0.70 to $0.90=$ high; and 0.90 to $1.00=$ very high). Linear regressions were used to calculate the coefficient of determination, and linear regressions with a restricted zero intercept were used to calculate the slope of the relationship between the BMC and visual observation data. Data from the BMC were considered precise if the $r$ and $R^{2}$ were high $(>0.70)$. Additionally, the $\rho_{\mathrm{c}}$ was calculated for all behaviors following Lin (1989). Results of the Lin's $\rho_{\mathrm{c}}$ were categorized by McBride $(2005 ;<0.90=$ poor; 0.90 to $0.95=$ moderate; 0.95 to $0.99=$ substantial; $>0.99$ $=$ almost perfect). Data from the BMC were considered accurate if the $\mathrm{r}$ and $\mathrm{R}^{2}$ were high $(>0.70)$, Lin's $\rho_{\mathrm{c}}$ was classified at least as moderate $(>0.90)$, and the slope of the regression analysis (not different from 1) and Bland-Altman plots were deemed accurate.

Bland-Altman plots (Bland and Altman, 1995a,b) were created for each behavior in Excel [Excel 2016 (v.16.0), Microsoft Corp., Redmond, WA]. The difference of collar and observed behaviors (collar - observed) for each cow's 240-min observation was used to calculate average bias of the 24 observed cows' difference. Standard deviation of the difference of collar and observed behaviors was calculated from all cow's 240-min observation. Standard deviation was then used to calculate the lower and upper limits of agreement [bias $\pm(1.96 \times \mathrm{SD})]$. The $\mathrm{x}$-axis showed the mean of the observed and collar recorded behavior [(observed + collar)/2] for each of the 24 cows plotted. The y-axis showed the difference of the observed compared with the collar-recorded behavior (collar - observed) for each of the 24 cows plotted. The BMC was considered accurate if the slope from the linear regressions did not differ significantly from 1 , and if the $95 \%$ interval of agreement included 0 for mean bias from the BlandAltman plots. Descriptive data measured by visual observation and BMC are presented in Table 2.

The $\mathrm{r}$ were $0.99,0.93$, and $0.94(P<0.001)$ for rumination time, feeding time, and resting time, respectively. The $\mathrm{R}^{2}$ were $0.97,0.85$, and $0.88(P<0.001)$ for rumination time (Figure 1a), feeding time (Figure 1b), and resting time (Figure 1c), respectively. The slope of regression was found to be 0.90 (CI: 0.87-0.93) for rumination time; $0.77(0.72-0.83)$ for feeding time; and 1.13 (1.07-1.19) for resting time. Concordance correlation coefficients $\left(\boldsymbol{\rho}_{\mathrm{c}}\right)$ were $0.95,0.80$, and 0.82 for rumination time, feeding time, and resting time, respectively.

A Bland-Altman plot was used to assess the differences between the collar and visual observations for rumination (Figure 2a), feeding (Figure 2b), and resting (Figure 2c). The 95\% confidence interval of the Bland-Altman plot encompassed all but one cow's observations for both rumination and feeding time, and all cows' resting time observations. Mean differences (BMC - observation) of the plots indicated whether the $\mathrm{BMC}$ was overestimating (positive bias) or underesti-

Table 2. Mean, minimum, and maximum time ( $\min )$ of lactating dairy cows spent ruminating, feeding, and resting, as recorded by visual observations and the behavior-monitoring collar $(\mathrm{BMC})^{1}$

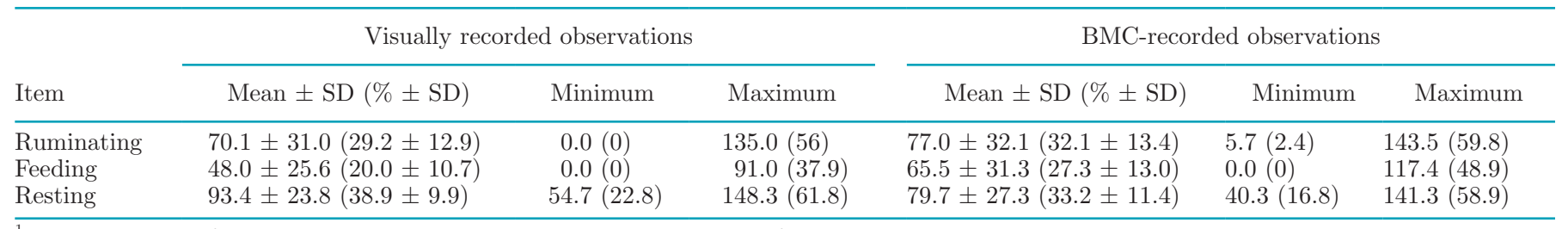

\footnotetext{
${ }^{1}$ The percentage of time spent displaying the corresponding behavior of the 240-min observation is given in parentheses.
} 


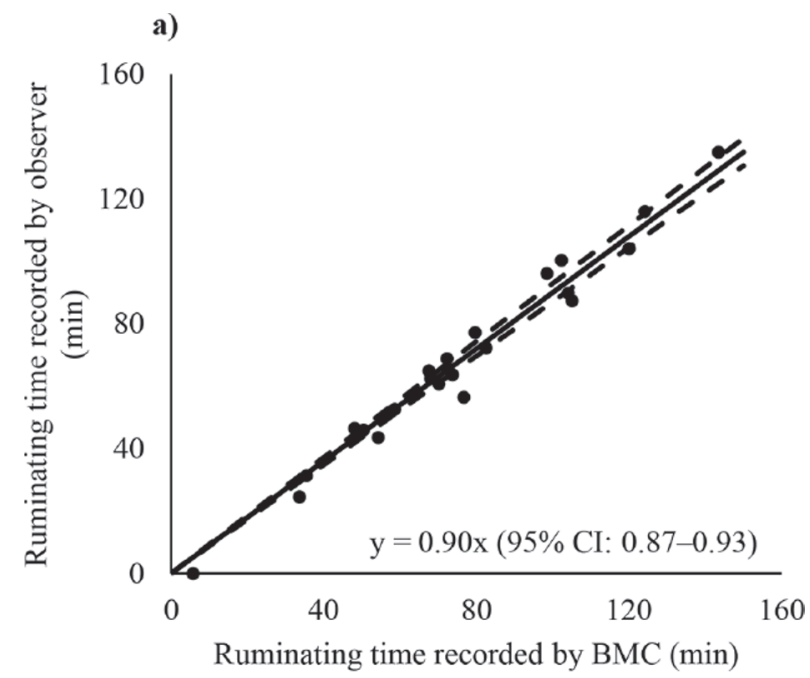

b)

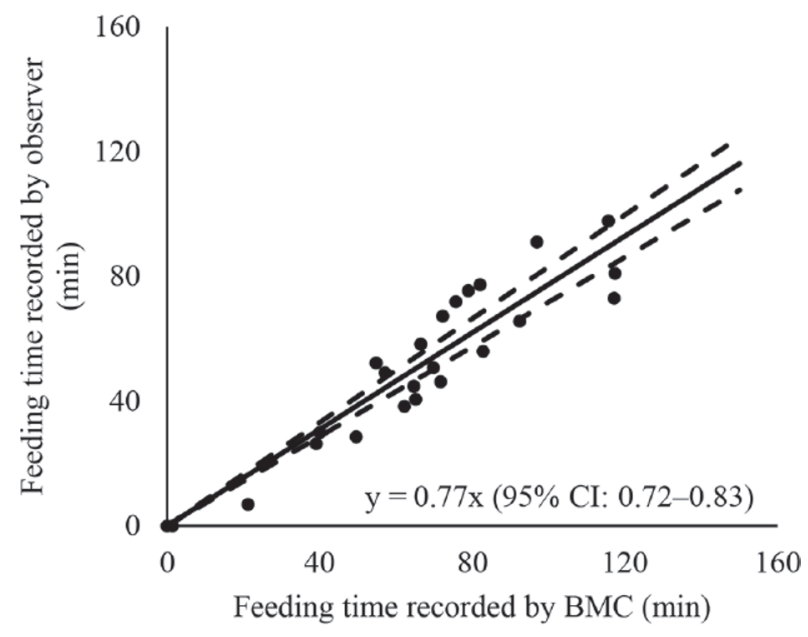

c)

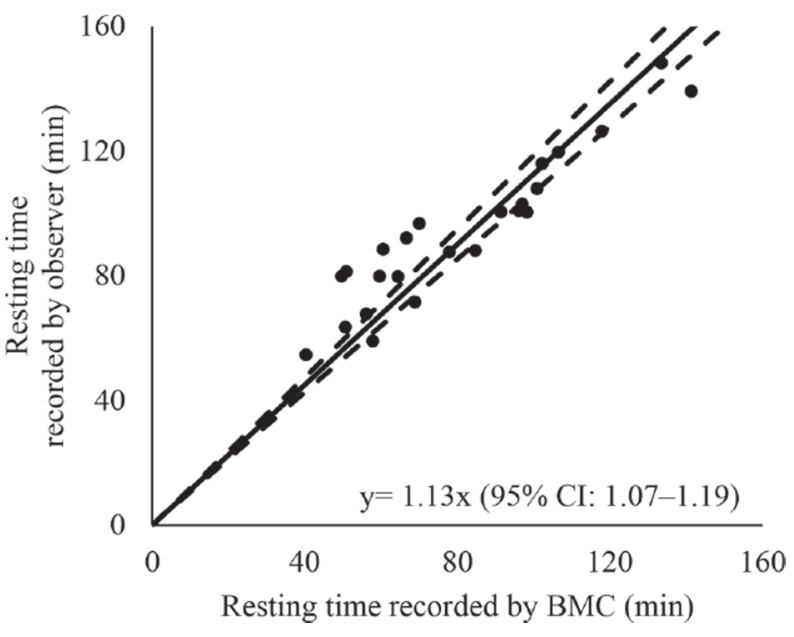

Figure 1. Regression of rumination (a), feeding (b), and resting (c), comparing the behavior-monitoring collar (BMC; x-axis) with visual observations (y-axis). Data points indicate total minutes each cow spent performing the corresponding behavior during the 240-min observation. mating (negative bias) behavior compared with visual observations. The results of the mean differences were rumination time: $-7.57 \pm 6.31 \mathrm{~min}$; feeding time: 15.81 $\pm 11.84 \mathrm{~min}$; and resting time: $-13.03 \pm 9.37 \mathrm{~min}$. The mean differences did, however, include zero within the $95 \%$ interval of agreement, indicating no difference between the BMC and visual observation. Precision and accuracy criteria results are shown in Table 3.

Precision dairy technology is useful to monitor behavior, or get alerts for abnormal cow behavior (Soriani et al., 2012). Cows have been reported to ruminate less if they are (or later become) diagnosed with metabolic disease(s) (Schirmann et al., 2016; Stangaferro et al., 2016a), or mastitis (Stangaferro et al., 2016b), or during the time around calving (Soriani et al., 2012; Calamari et al., 2014). Cows developing health disorders typically change activity to an extent that algorithms of the PDT can detect and report deviations of cow behavior, in comparison to normal (Stangaferro et al., 2016a). The MooMonitor+ collar used in this study yielded a high correlation of automated observations for feeding, ruminating, and resting behaviors in comparison to a trained observer. This finding is important for potential future large-scale implementation of the collar on-farm, because the automatic collection of data is precise. The BMC should detect the deviation in behavior, thus giving the producer an early warning to respond appropriately for the individual cow as needed.

Feeding and rumination time were in agreement with the visual data in this study. Precisely quantifying feeding and rumination is important because these behaviors decrease in cows that have been (or later become) diagnosed with metabolic disease (Goldhawk et al., 2009; Schirmann et al., 2016; Stangaferro et al., 2016a). The correlation of behavioral changes with metabolic disease gives producers the opportunity to detect onset of metabolic disease earlier because of the behavioral changes, which is important for cow welfare, maintaining milk production, and maintaining reproduction rates on farm. Additionally, feeding and rumination behavior deviating from normal during the period around calving may negatively affect cow reproduction (Wiltbank et al., 1962; Roche et al., 2000; Wiltbank et al., 2015). Although BMC feeding data were highly correlated with visual observations, further research should investigate the accuracy of PDT in different management and housing conditions.

The BMC found resting behavior to be in agreement with visual observation. Animals with metabolic diseases such as ketosis have been reported to lie more (Sepúlveda-Varas et al., 2014; Itle et al., 2015) or to be lethargic or depressed (Hart, 1988), making this behavior important to precisely assess over longer periods of time to detect animals at risk. 


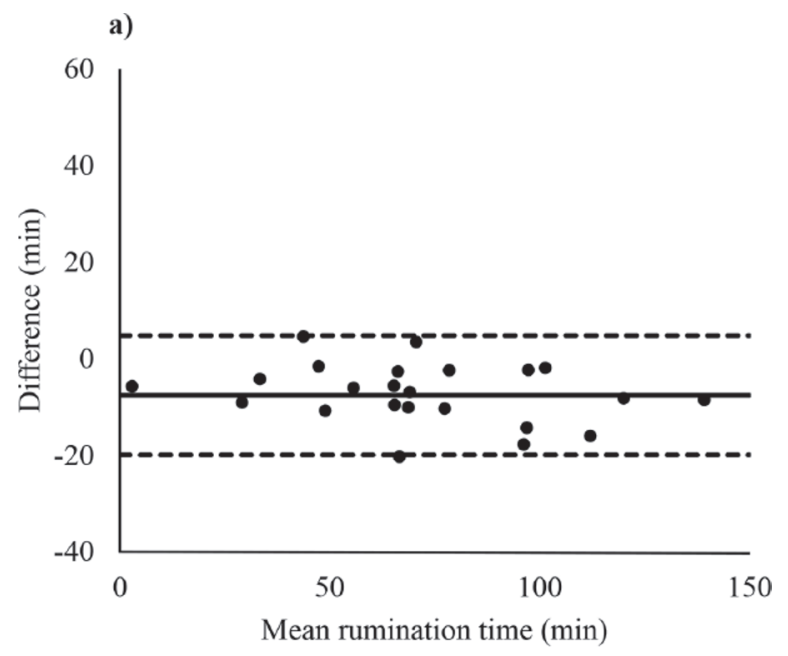

b)

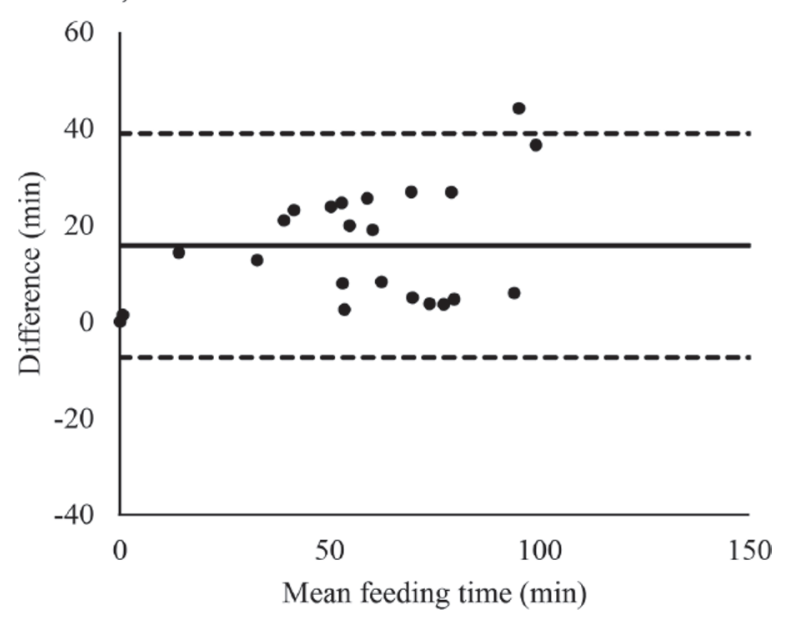

c)

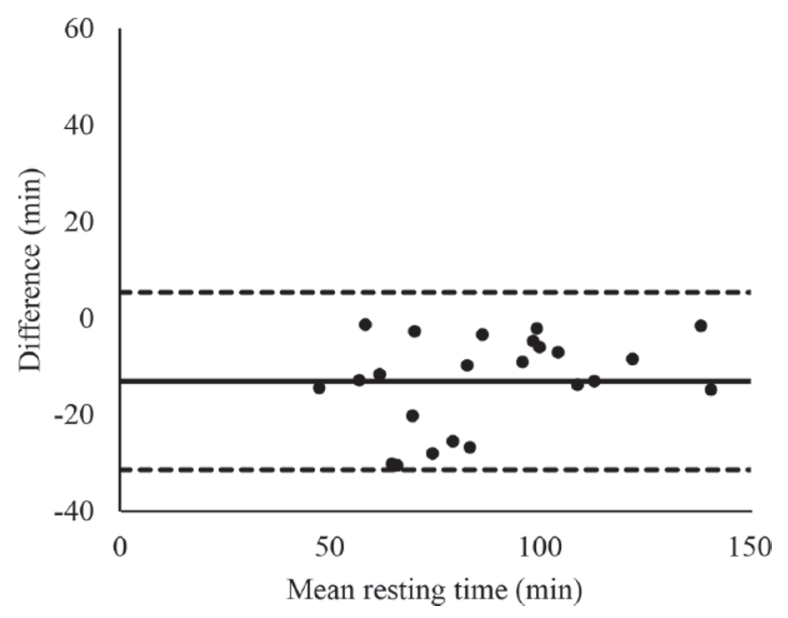

Figure 2. Bland-Altman plot illustrating agreement between the behavior-monitoring collar (BMC) and visual observations for ruminating (a), feeding (b), and resting (c). For all graphs, the x-axis is the mean of $\mathrm{BMC}$ and visual observation and the $\mathrm{y}$-axis is the difference between BMC-recorded behavior and visual observation (BMC - observed). Every data point on the graph is the result of each cow's agreement for the corresponding behavior.
We found the BMC to be very precise in measuring behavior of dairy cows, and it performed similarly to or better than other commercially available behaviormonitoring technologies. An accelerometer ear tag (ear tag 1) was validated by Bikker et al. (2014; freestallhoused dairy cows, TMR and partial mixed ration fed), Wolfger et al. (2015; steers housed on an outdoor dirt floor, bunk fed), Borchers et al. (2016; freestall-housed dairy cows, TMR fed), and Pereira et al. (2018; grazing dairy cows). All authors found good correlation for feeding when validating ear tag 1 ; however, the BMC validated in this study had better precision. Bikker et al. (2014) had very similar, high correlations for resting. Additionally, Bikker et al. (2014) reported ear tag 1 to have similar very high precision of rumination as the BMC; however, Wolfger et al. (2015), Borchers et al. (2016), and Pereira et al. (2018) reported a much lower correlation for rumination when validating ear tag 1 . Future research could compare the performance of PDT in different management styles and environments for precision and accuracy. Borchers et al. (2016) additionally validated 2 other accelerometer behavior-monitoring ear tags (ear tag 2 and ear tag 3 ), both reporting very high correlations for feeding and rumination behaviors, respectively. A collar using a combination of a microphone and an accelerometer was validated by Schirmann et al. (2009) was also very highly precise in addition to having a similar percentage of cows included in the $95 \%$ interval agreement of the Bland-Altman plot. A validation of a commercially available noseband pressure sensor by Zehner et al. (2017) reported similar values of accuracy and precision as the $\mathrm{BMC}$ in this study for ruminating and feeding. The BMC validated in this study had the same or higher accuracy as the noseband pressure sensor, depending on version of converter used by Zehner et al. (2017). The noseband pressure sensor studied by Zehner et al. (2017) was less precise at measuring feeding time when compared with the BMC.

Precise PDT can make a dairy more efficient by automating animal monitoring and alerting producers to cow behavior change (El-Osta and Morehart, 2000). Precision dairy technologies with low precision can lead to producers not acting on alerts (Eckelkamp, 2018). Inaccurate PDT will have either low sensitivity (true positives) or low specificity (true negatives), meaning it fails to alert (false negative) for a cow with abnormal behavior, needing attention, or falsely alerts (false positive) for cows with normal behavior, respectively. Eckelkamp (2018) noted that producers would often not act on alerts if the alerts were not believed. Additionally, PDT with low precision has the potential to be very expensive, for example by missed estrus detection, missed health events (Hogeveen et al., 2010; Rutten et 
Table 3. The results of the precision and accuracy test of rumination, feeding, and resting behaviors between visual observations and the behavior-monitoring collar $(\mathrm{BMC})^{1}$

\begin{tabular}{llll}
\hline Item & Ruminating & Feeding & Resting \\
\hline Pearson $\mathrm{r}$ & Yes & Yes & Yes \\
$\mathrm{R}^{2}$ & Yes & Yes & Yes \\
Concordance correlation coefficient $\left(\rho_{\mathrm{c}}\right)$ & Yes & No & No \\
Slope of the linear regression & No & No & No \\
Bland-Altman plots & No & No & Yes \\
All criteria & No & No & No \\
\hline
\end{tabular}

${ }^{1}$ Data from the BMC were considered precise if the $\mathrm{r}$ and $\mathrm{R}^{2}$ were high $(>0.70)$. The BMC was considered accurate if the slope from the linear regressions did not differ significantly from 1 , if visual analysis presented no bias on the Bland-Altman plots, and if all difference data were within the $95 \%$ interval of agreement.

al., 2013), or distributing treatment to healthy animals (Burfeind et al., 2011).

Accurate PDT provides real-time cattle monitoring tools for producers and data recording for management and comparisons (Norton and Berckmans, 2017). Highly accurate PDT can especially help producers running larger dairies without compromising integrity of animal care (Norton and Berckmans, 2017). Accuracy opens an opportunity for data to be compared across the industry, for example by comparing records between multiple farms, or for cross-sectional research. None of the 3 behaviors tested in this study met the slope criteria (slope not different from 1), and only rumination met the $\rho_{c}$ criteria established for accuracy. Most studies regarding validation of automated behavior monitoring devices have not presented data regarding the accuracy of the device. Future research should investigate the factors that affect accuracy of PDT. Additionally, few validation studies have investigated the accuracy of PDT; thus, there is a need to validate PDT in different environments and to determine how the accuracy of the technology is affected.

Overall, PDT aims to precisely record changes in behavior, therefore potentially detecting health or well-being issues before producers may have otherwise visually noticed the cow requiring intervention (Norton and Berckmans, 2017). Benefits of earlier observation or otherwise unnoticed cattle illness include preventing expensive treatments (Mazeris, 2010), reducing large production losses (Mazeris, 2010; Steensels et al., 2017), improving treatment implementation time (Goff, 2008; Sheldon et al., 2008; Lomander et al., 2012), and improving animal well-being (Steensels et al., 2017). Additional to producer uses, PDT with high accuracy can also aid researchers of dairy cows to collect a comprehensive data set. Practical PDT like the BMC in this study can be worn with little disruption to the cow, and take readings of behavior consistently, $24 \mathrm{~h} / \mathrm{d}$. Being able to rely on such a device could help researchers collect constant and consistent data without having to rely on visual observation. This could remove some limitations in dairy cow behavior studies such as interand intra-observer differences, enabling collection from all cows simultaneously and enabling data collection overnight in low visibility.

To our knowledge, this is the first validation study of the MooMonitor+ for ruminating, resting, and feeding in a confinement setting for lactating dairy cows. In this study, the BMC performed precisely, with very high correlations for ruminating, feeding, and resting behaviors.

\section{ACKNOWLEDGMENTS}

We gratefully acknowledge and thank the staff and students of the University of Kentucky's Coldstream Dairy Research Farm Farm (Lexington, KY) who helped in this experiment, especially Brittany Core, Amelia Fendley, Joey Clark, and Matt Collins. We are grateful to Jeffrey Bewley (CowFocused Housing, KY) and Matthew Borchers (Zoetis, Kalamazoo, MI) for helpful discussions on the topic of this study. We also thank Olga Vsevolozhskaya, Michelle Arnold, and Eric Vanzant from the University of Kentucky for their contribution in this project. This project was funded by DairyMaster (Co. Kerry, Ireland), through a research project partnership with the Dairy Science Program at the University of Kentucky.

\section{REFERENCES}

Ambriz-Vilchis, V., N. S. Jessop, R. H. Fawcett, D. J. Shaw, and A. I. Macrae. 2015. Comparison of rumination activity measured using rumination collars against direct visual observations and analysis of video recordings of dairy cows in commercial farm environments. J. Dairy Sci. 98:1750-1758. https://doi.org/10.3168/jds $.2014-8565$.

Bikker, J. P., H. van Laar, P. Rump, J. Doorenbos, K. van Meurs, G. M. Griffioen, and J. Dijkstra. 2014. Technical note: Evaluation of an ear-attached movement sensor to record cow feeding behavior and activity. J. Dairy Sci. 97:2974-2979. https://doi.org/10.3168/ jds.2013-7560. 
Bland, J. M., and D. G. Altman. 1995a. Calculating correlation coefficients with repeated observations: Part 1-Correlation within subjects. BMJ 310:446. https://doi.org/10.1136/bmj.310.6977.446.

Bland, J. M., and D. G. Altman. 1995b. Calculating correlation coefficients with repeated observations: Part 2-Correlation between subjects. BMJ 310:633. https://doi.org/10.1136/bmj.310.6980 633 .

Borchers, M. R., Y. M. Chang, I. C. Tsai, B. A. Wadsworth, and J. M. Bewley. 2016. A validation of technologies monitoring dairy cow feeding, ruminating, and lying behaviors. J. Dairy Sci. 99:74587466. https://doi.org/10.3168/jds.2015-10843.

Burfeind, O., V. S. Suthar, R. Voigtsberger, S. Bonk, and W. Heuwieser. 2011. Validity of prepartum changes in vaginal and rectal temperature to predict calving in dairy cows. J. Dairy Sci. 94:5053-5061. https://doi.org/10.3168/jds.2011-4484.

Caja, G., A. Castro-Costa, and C. H. Knight. 2016. Engineering to support wellbeing of dairy animals. J. Dairy Res. 83:136-147. https://doi.org/10.1017/S0022029916000261.

Calamari, L., N. Soriani, G. Panella, F. Petrera, A. Minuti, and E. Trevisi. 2014. Rumination time around calving: An early signal to detect cows at greater risk of disease. J. Dairy Sci. 97:3635-3647. https://doi.org/10.3168/jds.2013-7709.

Chizzotti, M. L., F. S. Machado, E. E. Valente, L. G. Pereira, M. M. Campos, T. R. Tomich, S. G. Coelho, and M. N. Ribas. 2015. Technical note: Validation of a system for monitoring individual feeding behavior and individual feed intake in dairy cattle. J. Dairy Sci. 98:3438-3442. https://doi.org/10.3168/jds.2014-8925.

DeVries, T. J., M. A. G. von Keyserlingk, and K. A. Beauchemin. 2003. Short communication: Diurnal feeding pattern of lactating dairy cows. J. Dairy Sci. 86:4079-4082. https://doi.org/10.3168/ jds.S0022-0302(03)74020-X.

Dolecheck, K. A., W. J. Silvia, G. Heersche, Y. M. Chang, D. L. Ray, A. E. Stone, B. A. Wadsworth, and J. M. Bewley. 2015. Behavioral and physiological changes around estrus events identified using multiple automated monitoring technologies. J. Dairy Sci. 98:8723-8731. https://doi.org/10.3168/jds.2015-9645.

Eckelkamp, E. A. 2018. On-farm utilization of precision dairy monitoring: Usefulness, accuracy, and affordability. PhD thesis. Department of Animal Science, University of Kentucky, Lexington. https: //doi.org/10.13023/ETD.2018.081.

El-Osta, H. S., and M. J. Morehart. 2000. Technology adoption and its impact on production performance of dairy operations. Rev. Agric. Econ. 22:477-498. https://doi.org/10.1111/1058-7195.00034.

Elischer, M. F., M. E. Arceo, E. L. Karcher, and J. M. Siegford. 2013. Validating the accuracy of activity and rumination monitor data from dairy cows housed in a pasture-based automatic milking system. J. Dairy Sci. 96:6412-6422. https://doi.org/10.3168/jds.2013 -6790 .

Friedman, H. 1982. Simplified determinations of statistical power, magnitude of effect and research sample sizes. Educ. Psychol. Meas. 42:521-526. https://doi.org/10.1177/001316448204200214.

Goff, J. P. 2008. The monitoring, prevention, and treatment of milk fever and subclinical hypocalcemia in dairy cows. Vet. J. 176:50-57. https://doi.org/10.1016/j.tvjl.2007.12.020.

Goldhawk, C., N. Chapinal, D. M. Veira, D. M. Weary, and M. A. G. von Keyserlingk. 2009. Prepartum feeding behavior is an early indicator of subclinical ketosis. J. Dairy Sci. 92:4971-4977. https:/ /doi.org/10.3168/jds.2009-2242.

Hart, B. L. 1988. Biological basis of the behavior of sick animals. Neurosci. Biobehav. Rev. 12:123-137. https://doi.org/10.1016/S0149 $-7634(88) 80004-6$

Hinkle, D. E. 1988. Applied Statistics for the Behavioral Sciences. 2nd ed. Houghton Mifflin, Boston, MA.

Hogeveen, H., C. Kamphuis, W. Steeneveld, and H. Mollenhorst. 2010. Sensors and clinical mastitis - The quest for the perfect alert. Sensors (Basel) 10:7991-8009. https://doi.org/10.3390/s100907991.

Itle, A. J., J. M. Huzzey, D. M. Weary, and M. A. G. von Keyserlingk. 2015. Clinical ketosis and standing behavior in transition cows. J. Dairy Sci. 98:128-134. https://doi.org/10.3168/jds.2014-7932.
Lin, L. I.-K. 1989. A concordance correlation coefficient to evaluate reproducibility. Biometrics 45:255-268. https://doi.org/10.2307/ 2532051.

Lomander, H., J. Frössling, K. L. Ingvartsen, H. Gustafsson, and C. Svensson. 2012. Supplemental feeding with glycerol or propylene glycol of dairy cows in early lactation-effects on metabolic status, body condition, and milk yield. J. Dairy Sci. 95:2397-2408. https: //doi.org/10.3168/jds.2011-4535.

Mazeris, F. 2010. DeLaval Herd Navigator: Proactive herd management. Pages 26-27 in Proc. First North American Conference on Precision Dairy Management. Toronto, Ontario, Canada.

McBride, G. B. 2005. A proposal for strength-of-agreement criteria for Lin's Concordance Correlation Coefficient. NIWA Client Report: HAM2005-062.

Norton, T., and D. Berckmans. 2017. Developing precision livestock farming tools for precision dairy farming. Anim. Front. 7:18-23. https://doi.org/10.2527/af.2017.0104.

NRC. 2001. Nutrient Requirements of Dairy Cattle. 7th rev. ed. The National Academies Press, Washington, DC. https://doi.org/10 $.17226 / 9825$.

Pereira, G. M., B. J. Heins, and M. I. Endres. 2018. Technical note: Validation of an ear-tag accelerometer sensor to determine rumination, eating, and activity behaviors of grazing dairy cattle. J. Dairy Sci. 101:2492-2495. https://doi.org/10.3168/jds.2016-12534.

Roche, J. F., D. Mackey, and M. D. Diskin. 2000. Reproductive management of postpartum cows. Anim. Reprod. Sci. 60-61:703-712. https://doi.org/10.1016/S0378-4320(00)00107-X.

Rutten, C. J., A. G. J. Velthuis, W. Steeneveld, and H. Hogeveen. 2013. Invited review: Sensors to support health management on dairy farms. J. Dairy Sci. 96:1928-1952. https://doi.org/10.3168/ jds.2012-6107.

Schirmann, K., M. A. G. von Keyserlingk, D. M. Weary, D. M. Veira, and W. Heuwieser. 2009. Technical note: Validation of a system for monitoring rumination in dairy cows. J. Dairy Sci. 92:6052-6055. https://doi.org/10.3168/jds.2009-2361.

Schirmann, K., D. M. Weary, W. Heuwieser, N. Chapinal, R. L. A Cerri, and M. A. G. von Keyserlingk. 2016. Short communication: Rumination and feeding behaviors differ between healthy and sick dairy cows during the transition period. J. Dairy Sci. 99:99179924. https://doi.org/10.3168/jds.2015-10548.

Sepúlveda-Varas, P., D. M. Weary, and M. A. G. von Keyserlingk. 2014. Lying behavior and postpartum health status in grazing dairy cows. J. Dairy Sci. 97:6334-6343. https://doi.org/10.3168/ jds.2014-8357.

Shahriar, M. S., D. Smith, A. Rahman, M. Freeman, J. Hills, R. Rawnsley, D. Henry, and G. Bishop-Hurley. 2016. Detecting heat events in dairy cows using accelerometers and unsupervised learning. Comput. Electron. Agric. 128:20-26. https://doi.org/10.1016/ j.compag.2016.08.009.

Sheldon, I. M., E. J. Williams, A. N. A. Miller, D. M. Nash, and S. Herath. 2008. Uterine diseases in cattle after parturition. Vet. J. 176:115-121. https://doi.org/10.1016/j.tvjl.2007.12.031.

Soriani, N., E. Trevisi, and L. Calamari. 2012. Relationships between rumination time, metabolic conditions, and health status in dairy cows during the transition period. J. Anim. Sci. 90:4544-4554. https://doi.org/10.2527/jas.2012-5064

Sprecher, D. J., D. E. Hostetler, and J. B. Kaneene. 1997. A lameness scoring system that uses posture and gait to predict dairy cattle reproductive performance. Theriogenology 47:1179-1187. https:// doi.org/10.1016/S0093-691X(97)00098-8.

Stangaferro, M. L., R. Wijma, L. S. Caixeta, M. A. Al-Abri, and J. O. Giordano. 2016a. Use of rumination and activity monitoring for the identification of dairy cows with health disorders: Part I. Metabolic and digestive disorders. J. Dairy Sci. 99:7395-7410. https:// doi.org/10.3168/jds.2016-10907.

Stangaferro, M. L., R. Wijma, L. S. Caixeta, M. A. Al-Abri, and J. O. Giordano. 2016b. Use of rumination and activity monitoring for the identification of dairy cows with health disorders: Part II. 
Mastitis. J. Dairy Sci. 99:7411-7421. https://doi.org/10.3168/jds 2016-10908.

Steensels, M., E. Maltz, C. Bahr, D. Berckmans, A. Antler, and I. Halachmi. 2017. Towards practical application of sensors for monitoring animal health; design and validation of a model to detect ketosis. J. Dairy Res. 84:139-145. https://doi.org/10.1017/ S0022029917000188.

Wiltbank, J. N., W. W. Rowden, J. E. Ingalls, K. E. Geegoey, and R. M. Koch. 1962. Effect of energy level on reproductive phenomena of mature Hereford cows. J. Anim. Sci. 21:219-225. https://doi .org $/ 10.2527 /$ jas1962.212219x.

Wiltbank, M. C., R. R. Grummer, R. D. Shaver, J. E. Santos, R. Sartori, P. D. Carvalho, A. H. Souza, and M. Z. Toledoa. 2015. Nutrition and reproductive efficiency: Transition period manage- ment, energy status, and amino acid supplementation alter reproduction in lactating dairy cows. Pages 39-54 in Proc. 2015 Florida Ruminant Nutrition Symposium; Feb. University of Florida IFAS Extension, FL.

Wolfger, B., E. Timsit, E. A. Pajor, N. Cook, H. W. Barkema, and K. Orsel. 2015. Technical note: Accuracy of an ear tag-attached accelerometer to monitor rumination and feeding behavior in feedlot cattle. J. Anim. Sci. 93:3164-3168. https://doi.org/10.2527/jas .2014-8802.

Zehner, N., C. Umstätter, J. J. Niederhauser, and M. Schick. 2017. System specification and validation of a noseband pressure sensor for measurement of ruminating and eating behavior in stable-fed cows. Comput. Electron. Agric. 136(Supplement C):31-41. https:/ /doi.org/10.1016/j.compag.2017.02.021. 